\section{Alzheimer's Disease Silent Killer of Memory: A Review on Pathological Mechanisms}

\author{
Arti Rana ${ }^{1}$, Anupam Awasthi ${ }^{1}$, Deepak Kumar ${ }^{1}$, Sukhjinder \\ Singh $^{2}$ and Shamsher Singh ${ }^{1 *}$ \\ ${ }^{1}$ Department of Pharmacology, ISF College of Pharmacy, Punjab, India \\ ${ }^{2}$ Department of Pharmacology, Postgraduate Institute of Medical Education \\ \& Research, Chandigarh, India
}

\begin{abstract}
tive therapeutic drugs and increased severity of $A D$ day by day is a big challenge for against researchers. Therefore this review basically focused to explore the underlying pathological mechanism behind neuronal dysfunctioning and the various pathways involved in the pathogenesis of $A D$.
\end{abstract}

Keywords: Alzheimer's disease; Beta-amyloid; Caspases; Neurofibrillary tangles; Oxidative stress; Tau protein

\author{
Abbreviations \\ $\mathrm{AD}$ - Alzheimer's Disease \\ AB - Amyloid Beta \\ NFTs - Neurofibrillary Tangles \\ CASP - Caspases \\ TNF- $\alpha$ - Tumor Necrosis Factor \\ APP - Amyloid Precursor Protein \\ ROS - Reactive Oxygen Species \\ IL - Interleukins
}

\section{Introduction}

Alzheimer's Disease (AD) is a slowly progressive neurological disorder characterized by impairment of memory and ultimately disturbances in learning, reasoning, planning, language, and perception [1]. It is also known as Senile Dementia of the Alzheimer Type (SDAT). Globally more than 45 million peoples are living with dementia, most suffering from AD. The prevalence of dementia will reach 75.6 million in 2030 and 135.5 million in 2050, of which $6.46 \%$ are from USA [2]. Many scientists believe that AD results from an increased oxidative stress due to the accumulation of a specific protein (beta-amyloid protein) in the brain that leads to neuronal cell death [3].

$\mathrm{AD}$ has been named after the German psychiatrist Alois Alzheimer who first described this disease in 1901 in Auguste D, a 50-yearold lady. Depending on its time of onset AD may be; Early-onset AD (usually affecting people aged 30 to 60 years) and Late-onset AD (this generally disturbs people over age 65 years) [4]. In AD patient may face problems in recognizing family and friends due to excessive neurodegeneration or neurotransmitter imbalance. The common symptoms in AD include alteration in mood, behavioral, hallucinations, and delirium. It usually starts slowly, silently and gets worse over time. With the advancement of disease physiological symptoms also alter like problems with language, alteration of mood, loss of inspiration and behavioral issues [5]. As a person's condition declines, she or he often withdraws from family and society, gradually body functions are lost leading to neuronal loss and death.

In addition, the accumulation of neurofibrillary tangles, free radical damage, low antioxidant enzymes level (Superoxide Dismutase (SOD) and catalase), mitochondrial failure have been observed in AD patients [6]. The increased oxidative damage to lipids and proteins with reduced activity of glutathione and other antioxidant enzyme are 
more localized to the neuronal junctions and correlate with the severity of the disease, suggesting to plays key role in AD-related neurodegenerative disorders [7]. The postmortem reports suggest that oxidative stress may be one of the prominent factors that is responsible for the initiation and development of AD. The exact pathophysiology of $\mathrm{AD}$ is still inadequately understood but mitochondria dysfunction and reduced level of pericyte are the progressive pathological factors [8].

Available evidence indicates that fragmentation of Golgi body increase Amyloid Precursor Protein (APP) trafficking and increase Amyloid Beta $(A \beta)$ accumulation [9]. Joshi, et al., has suggested that the accumulation of $A \beta$ peptides which leads to fragmentation of Golgi complex [10]. Nearly $70 \%$ risks of factors are of genetic background due to the involvement of various genes [11]. Additional risk factors include: person suffering from depression, accidental brain injury or hypertension. The major hallmark includes deposition of protein plaques (Tau proteins) and neurofibrillary tangles in the brain [12].

Nowadays there is no specific treatment available to prevent $\mathrm{AD}$ but the non-pharmacological measures like physical exercise as well as reducing body fat may decrease the risk of AD. Some of the antioxidants and vitamins from a long time are being under pre-clinical evaluation but these supplements cannot cure AD entirely or reverse its progression, though for the moment reduce symptoms [13]. Several drug therapies are available but they provide symptomatic relief to the patient suffering from this disease. The patients suffering from this disease become dependent on others for their daily life activities often increase a burden on the caregiver. Exercise programs are advantageous in the daily life and potentially improve outcomes. Antipsychotic agents are commonly used for the management of behavioral or psychotic problems due to dementia but not usually recommended due to their stumpy brain penetration and less therapeutic potential. Hence further studies are required to explore the hidden targets to achieve better drug therapy to secure life [14].

\section{Pathophysiological Mechanisms in Alzheimer's Disease}

\section{Role of Amyloid Beta (Aß) in neurodegeneration}

Amyloid Beta $(\mathrm{A} \beta)$ is peptides of $40-42$ amino acids which produce various pathological changes in $\mathrm{AD}$ [15]. The accumulation of the proteins like $\beta$-amyloid is responsible for structural changes in $\mathrm{AD}$ [16]. The peptides are formed by proteolytic cleavage of the large transmembrane Amyloid Precursor Protein (APP) by $\beta$ and $\gamma$ secretases. These $A \beta$ protein molecules can combine to form oligomeric bundles which are soluble and also exist in several forms [17]. It is hypothesized that there are certain misfolded oligomers (known as "seeds") responsible for inducing or misfolding of other $\beta$-amyloid molecules by a series of a chain reaction. This results in accumulation of $\beta$-amyloid and produces a toxic effect in the nerve cells [18]. The other type of protein present in $\mathrm{AD}$ is tau proteins which also exist in misfolded oligomers. The number of evidence support that misfolded $\mathrm{A} \beta$ can induce misfolding of tau protein. The actual physiological function of $A \beta$ is not fully clear but some animal study reports have shown that the lack of $A \beta$ proteins does not lead to loss of any physiological function [19]. There are several potential actions have been exposed for $A \beta$, including activation of kinase family of enzymes, defense against oxidative stress, lowering or regulation of cholesterol transport, and anti-microbial activity (mainly related to A $\beta$ 's pro-inflammatory activity). The lymphatic system is responsible for clearance of $\beta$-Amyloid proteins from the mammalian brain particularly but the pace of elimination is significantly increased during the sleeping time [20]. A $\beta$ proteins are by the sequential cleavage of the Amyloid Precursor Protein (APP) through the action of $\beta$ and $\gamma$ secretases respectively [21]. A number of isoforms (36-43 amino acid residues in length) are generated by the action of $\gamma$ secretases on the C-terminal end of the $A \beta$ peptide. The $A \beta 40$ and $A \beta 42$ are the most common isoform, produced by cleavage in the endoplasmic reticulum and trans-Golgi network respectively [22]. The A $\beta 40$ is the more common form than $A \beta 42$ but $A \beta 42$ is fibrillogenic and therefore responsible for the disease states [23]. The increased production of A $\beta 42$ has been noted during the mutations in APP responsible for early-onset Alzheimer's which suggested the involvement of modulation of the activity of $\beta$ and $\gamma$ secretases as a possible therapy for Alzheimer's disease.

In 2010 it was noted that the structural sequence on the oligomeric state of amyloid beta is still sparse. Low-temperature and low-salt conditions allowed isolating pentameric disc-shaped oligomers devoid of beta structure [24]. The amyloid beta after accumulation cause loss of neuronal functioning by inhibiting mitochondrial function, increase generation of ROS, further cause's lipid peroxidation and the generation of a toxic aldehyde called 4-hydroxynonenal which in turn decreases ATPase's activity, glucose transport and consequently neuronal loss occur. The $\beta$ amyloid increases glutamate-dependent depolarization of the synaptic membrane which increases calcium influx dependent mitochondrial impairment [25]. Amyloid hypothesis stated that the fundamental cause of $\mathrm{AD}$ is extracellular Amyloid Beta $(\mathrm{A} \beta)$ deposits. This postulate has been evidenced by the position of the gene that regulates Amyloid Precursor Protein (APP) on chromosome 21 , implying that individuals with Down's syndrome develop typical Alzheimer neuropathology because they produce too much $A \beta$ lifelong [26]. Another fact that supports the above-mentioned postulate is that the people with trisomy 21 almost universally exhibit $\mathrm{AD}$ by 40 years of age [27]. Also, a specific form of Apolipoproteins (ApoE4) is the strongest known genetic risk factor for the late onset of $\mathrm{AD}$ [28]. Further, in the transgenic mice, it has been seen that those mice which express a mutant type of the human APP gene are more prone toward the development of fibrillary amyloid plaques and have more chances of $\mathrm{AD}$. An experimental vaccine was used in early human trails to find out its effect for clearing the amyloid plaque but it was only effective for the clearance of plaque without significant effect on dementia. Researchers have been led to suspect non-plaque $A \beta$ oligomers as the primary pathogenic form of $A \beta$. These noxious protein oligomers are also known to as Amyloid-Derived Diffusible Ligands (ADDLs). These oligomers easily bind to a cell membrane receptor of neurons and modify the structure of the synapse thereby distracting neuronal communication. A single receptor for $A \beta$ protein oligomers may behave like prion protein, i.e. the same proteins which are associated with disease and the related human situation like Creutzfeldt-Jakob [29] (Figure 1).

Golgi body and Amyloid beta protein: Available experimental reports suggest that the inhibitors of plasminogen activator inhibitor- 1 decrease the plasma and brain $A \beta$ levels in transgenic animals. Amyloid targeting immunotherapy can be done by bapineuzumab, gantenerumab etc. These monoclonal humanized antibodies mainly act on the CNS reduce Tau proteins level either by inhibiting their 
phosphorylation or clearance mechanism [30]. Exogenous antioxidants are being used like flavonoids, carotenoids and ubiquitous antioxidants show a powerful neuroprotective effect but have some bioavailability problems. The previous finding has reported that rutin, lutein, and curcumin also attenuates $A \beta$ induced inflammation and reasonably inhibits $\beta$-secretase and AChE [31]. Normally the A $\beta$ are matured and released by Golgi body but excessive accumulation or tauopathy cause fragmentation of this Golgi assembly that leads to loss of functioning [10].

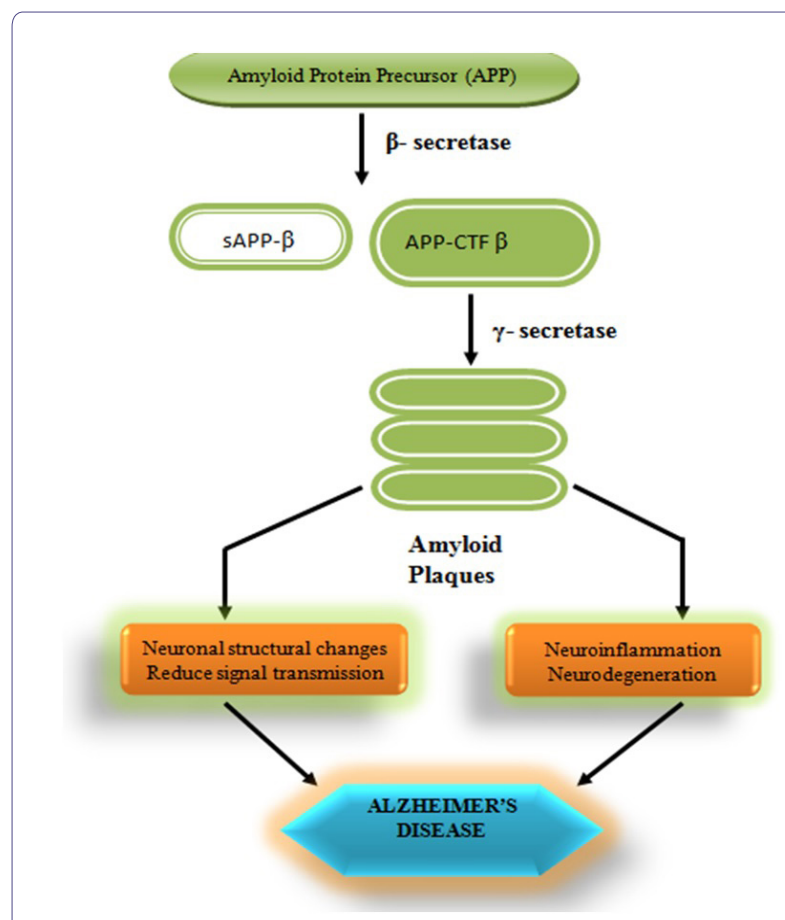

Figure 1: Formation of $\beta$ amyloid plaques in Alzheimer's disease.

APP: Amyloid Protein Precursor; sAPP- $\beta$ : soluble Amyloid Protein Precursor-Beta; APP-CTF $\beta$ : Amyloid Protein Precursor-C-Terminal Fragment-Beta

\section{Role of Tau protein in Alzheimer's disease}

$\mathrm{AD}$ also has a concern with abnormal aggregation of tau protein in the neurons and therefore it is also considered as tauopathy. Normally these tau proteins are present in neurons which helps to stabilize the microtubules during phosphorylation and therefore known as microtubule coupled protein [32]. In $\mathrm{AD}$, a tau protein undergoes chemical alterations, become hyperphosphorylated and starts to form a couple with other and thus appear like Neurofibrillary Tangles (NFTs). The presence of NFTs disrupts normal synaptic plasticity, which would lead to a diminution in neurotransmission, death of neurons bearing tangle and dementia [33].

The tau hypothesis, has proposed that any structural and functional tau protein abnormalities initiate' disease cascade or disease like condition. Once the hyperphosphorylated tau accumulates inside nerve cell bodies, they cause disintegration of microtubules, destroy the cell's cytoskeleton that collapses the neuron transport system [34]. This may lead to malfunction of neurochemical communication among neurons that can cause neuronal loss or death [35]. Thus, according to Tau hypothesis it is believed that the abnormal aggregation of the tau protein is the cause of AD. Neurofibrillary tangles are thought to develop when an unknown trigger leads to the dissociation of tau from microtubules. Some studies revealed that hyperphosphorylated tau accumulates as tangles even when tau levels are decreased by transgenic suppression. This might be due to the action of tangles as a sink for tau intermediates that are predicted to have formed as part of the pathogenic process [33]. However, tangle formation is not associated directly with cognitive decline, which suggests that tau intermediates are the neurotoxic species; similar intermediates composed of other proteins such as Huntington or $A \beta$ protein have been suggested to be neurotoxic elements in other diseases [36].

Tau-base targeted strategies prevent Alzheimer's disease: Tau protein accumulation due to hyperphosphorylation loses microtubule binding and stabilizing role, contributing to neuronal deterioration [37]. Targeting tau phosphorylation is in basically needed to focus on Glycogen Synthase Kinase-3 (GSK3), one of the primary enzymes concerned in tau phosphorylation. A temperate improvement in mood (particularly apathy) and social interaction has been observed with cholinesterase inhibitors treatment [38]. Recent studies revealed that caffeine shows an inhibitory effect on Phosphodiesterease (PDE) enzyme and it also inhibits GSK3b. Microtubule stabilization criteria can be adopted in which the administration of paclitaxel (i.e. microtubule stabilizer) to tau-transgenic mice significantly improves fast axonal transport, microtubule density, and motor function. Epothilone $\mathrm{D}$, is a potent inhibitor of active transporter which is also used as microtubule stabilizer is known for its good blood-brain barrier elimination [39]. Rojo, et al., has suggested that the lansoprazole and astemizole (both benzimidazole derivatives) bind with tau protein and in reducing the formation of neurofibrillary tangles. Enhancing tau degradation helps to augment the degradation of polymerized tau, thus declining its toxicity. Another, heat shock protein 90 (Hsp 90), also help to the denatured proteins, seems to play a role in preventing tau degradation [40]. Tau immunotherapy is successful for passive immunization with monoclonal antibodies decreases the phosphorylated tau molecules to reduce disease instances [41] (Figures 2\&3).

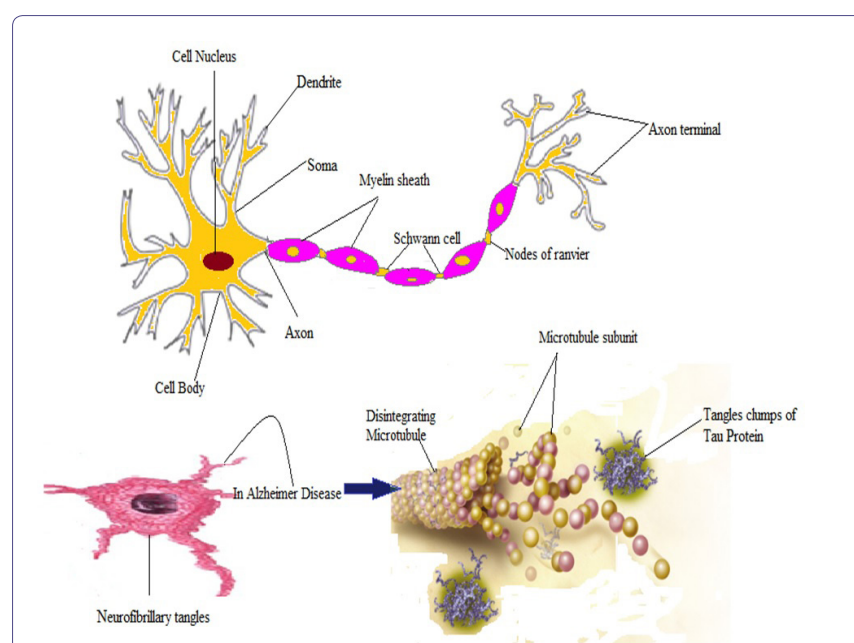

Figure 2: Formation of neurofibrillary tangles and tau protein clumps in Alzheimer's disease. 


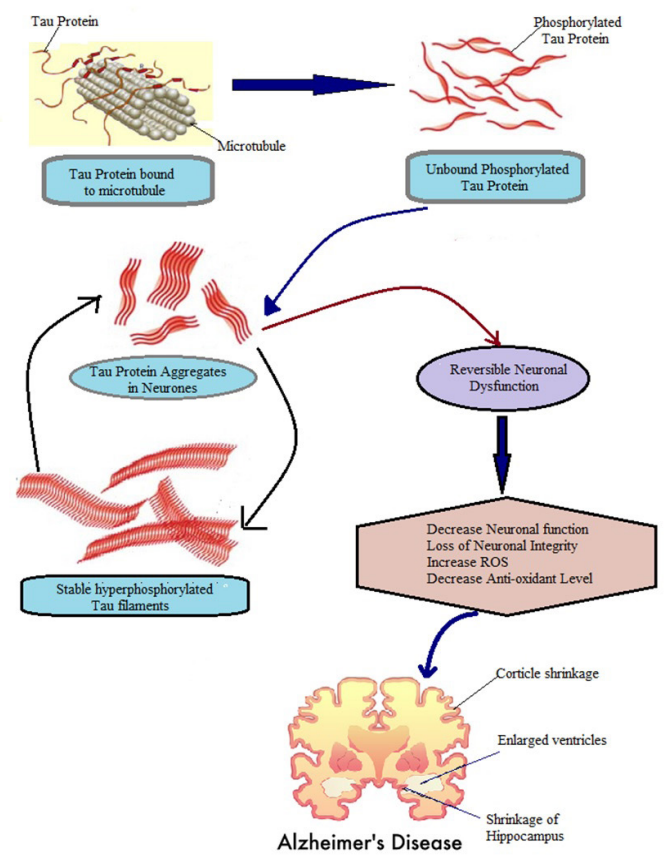

Figure 3: Role of Tau protein in Alzheimer's disease.

Role of Pericyte in Alzheimer's disease: Pericytes are individually situated in the neurovascular unit between endothelial cells of brain capillaries, astrocytes and neurons. Pericytes are cells in the Blood-Brain Barrier (BBB) which elevates the amyloid $\beta$-peptide $(A \beta)$, cause tau pathology and neuronal loss that leads to progressive cognitive decline and dementia [42]. Most of the studies have shown that pericytes regulate key neurovascular functions including BBB formation and maintenance, regulation of capillary blood flow and clearance of toxic cellular by products necessary for normal functioning of the Central Nervous System (CNS). Abhay, et al., has observed that the pericytes control multiple steps of AD-like neurodegeneration pathogenic cascade in $A \beta$-precursor protein in mice (Figure 4).

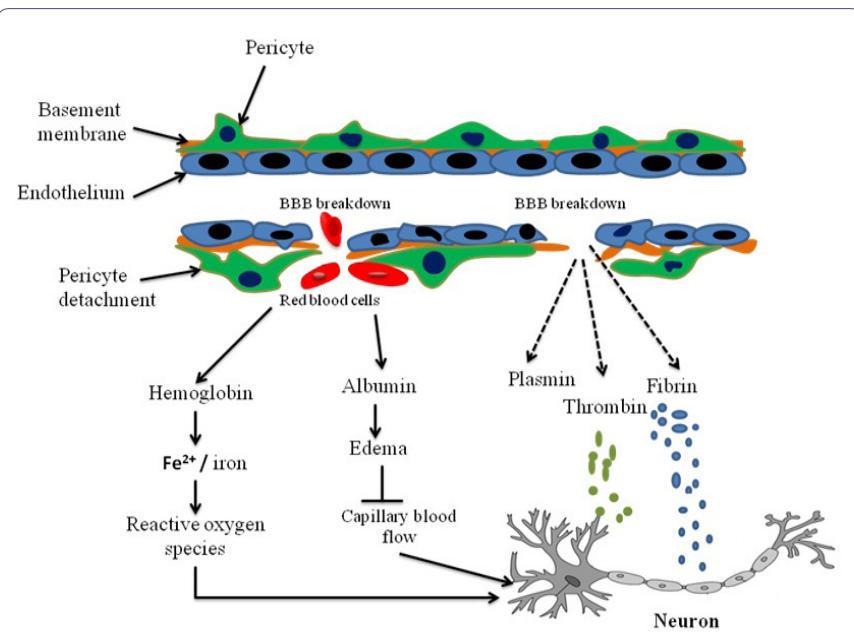

Figure 2: Role of pericyte in Alzheimer's disease.

\section{Role of Oxidative Stress in Alzheimer's disease}

Oxidative stress creates inequality between the formation of Reactive Oxygen Species (ROS) and their neutralization by biological systems. Any change in usual redox state of cells or neurons may show toxic effects through the formation of peroxides and other free radicals species that damage to various cellular components like proteins, lipids and DNA. Further, these negative charge species behave like cellular messengers in redox cell signaling which can interfere with the mechanisms of cellular processing [43]. Oxidative damage caused by these negative charge species can further target intracellular structures decrease mitochondrial metabolism which act as causative factors of abnormal function and cause cell death [44]. In the cells, mitochondria produce ATP, which is essential for the neurons survival and functional impairment results in neurodegeneration. Interestingly, vascular hypoperfusion is responsible for the dysfunction of mitochondria in AD with subsequent RNA oxidation, lipid peroxidation or mitochondrial DNA deletion [45]. Mitochondria are the major site involved in the generation of free radicals like $\mathrm{O}_{2}{ }^{-}$and $\mathrm{H}_{2} \mathrm{O}_{2}$ respectively. It is well reported that increases in mitochondrial DNA in the cell soma of AD susceptible neurons can itself cause increased oxidative potential [46].

Increased oxidative stress and low cellular defense directly move the cells toward decay which can be reversed by enhancing antioxidants levels, such as glutathione. The detrimental effects of oxidative stress cause structural damage, cellular apoptosis which finally leads to necrosis. Production of ROS is a particularly destructive aspect of the cellular growth [47]. Some of the less reactive species (such as superoxide) can be converted into more destructive radical species by redox reactions with transition metals or other redox cycling compounds (including quinones) that can cause extensive cellular damage.

Similarly, the long-term effects are caused by damage to DNA which may be induced by ionizing radiation that is similar to oxidative stress and these lesions are mostly implicated in aging and cancer [48]. Some time the high-intensity radiation can cause single-base dents like 8-oxoguanine and thymine glycol and their biological effects have been studied extensively. Most of the oxygen-derived species responsible for oxidative stress cause necrosis are formed during normal cellular aerobic metabolism. The antioxidants are capable of destroying most of these oxygen derived species and any damage to cells is continually repaired. But under some harmful, conditions these species can cause necrosis leads to ATP depletion and finally delay the regeneration of the cells. Xanthine oxidase, NADPH oxidases, and cytochromes $\mathrm{P} 450$ are some of the other enzymes which are capable of producing superoxides [49]. Thus, to improve the cellular survival a balance must be necessary between production and consumption of free radical species. Disrupted mitochondrial respiratory ATP synthesis caused by oxidative stress leads to neurodegeneration followed by $\mathrm{AD}$, Parkinson's disease and other neurodegenerative diseases [50].

Hypoxia exercise induces overproduction of (ROS) and RNS and alters redox balance. Infact, both acute and long-term hypoxic exposures have been shown to enhance the oxidative stress whereas increased oxidative stress has been observed in hypobaric as well as normobaric hypoxia (i.e., simulated altitude). Debevec, et al., has indicated that hypobaric hypoxia might induce higher oxidative stress levels than normobaric hypoxia [51] (Figure 5). 


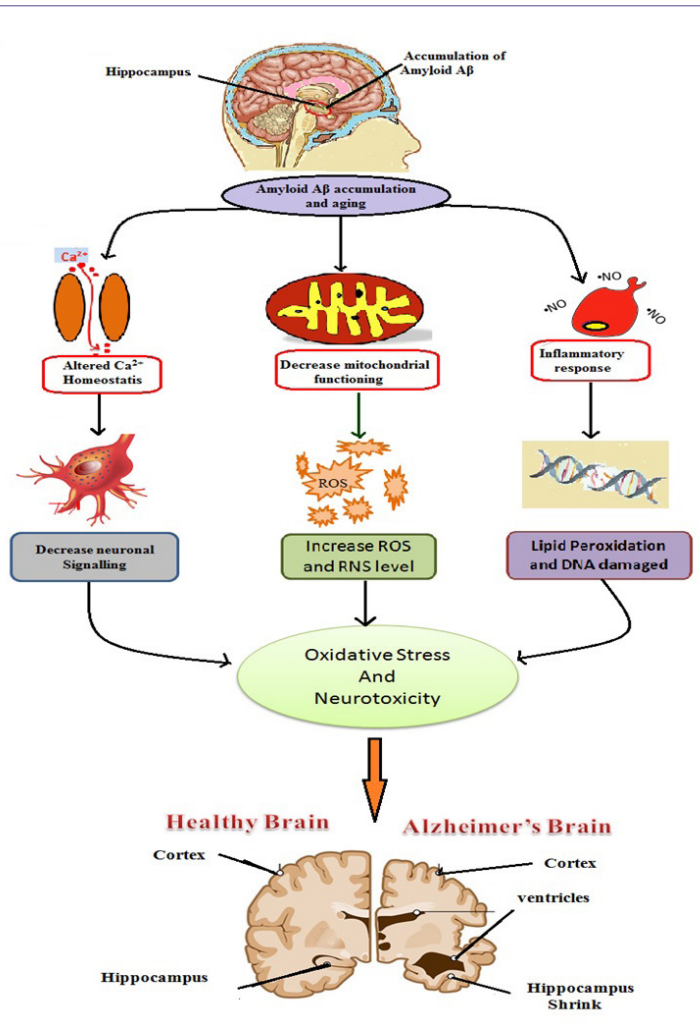

Figure 5: Effect of oxidative stress and mitochondrial failure in AD.

\section{Role of Caspase in Alzheimer's Disease}

Caspases also called cysteine-aspartic proteases are consist of a large number of cysteine proteases that play crucial roles in programmed cell death and initiate inflammatory responses [52]. Caspases are also termed "executioner" molecules because of their roles in the cellular signaling. Some caspases are reported to have their useful function in the immune response regulation because they help in the maturation of lymphocytes. Stoppage of apoptosis can contribute to tumor progression and autoimmune diseases that can initiate unwanted apoptosis commonly occur with ischemia or Alzheimer's disease [53]. There are two types of apoptotic caspases: initiator (apical) caspases and effector (executioner) caspases. Initiator caspases (e.g., CASP2, CASP8, CASP9, and CASP10) cleave inactive pro-forms of effector caspases, thereby activating them. Effector caspases (e.g., CASP3, CASP6 and CASP7) in turn cleave other protein substrates within the cell, to trigger the apoptotic process [54] (Figure 6).

It is well reported in various studies that the Amyloid Precursor Protein (APP) is a substrate for caspase-3-mediated cleavage, which may contribute to $A \beta$ formation, synaptic loss, and the behavioral changes associated with AD. The principle hypothesis supporting this study was obtained using a site-directed Caspases-cleavage antibody to APP. In consideration to this report lot of studies have put forward and been able to demonstrate the caspases cleavage of fodrin in the $\mathrm{AD}$ brain as well as the activation of specific initiator and executioner caspases including caspase-3, 6, 8, and 9 [55] (Figure 7).
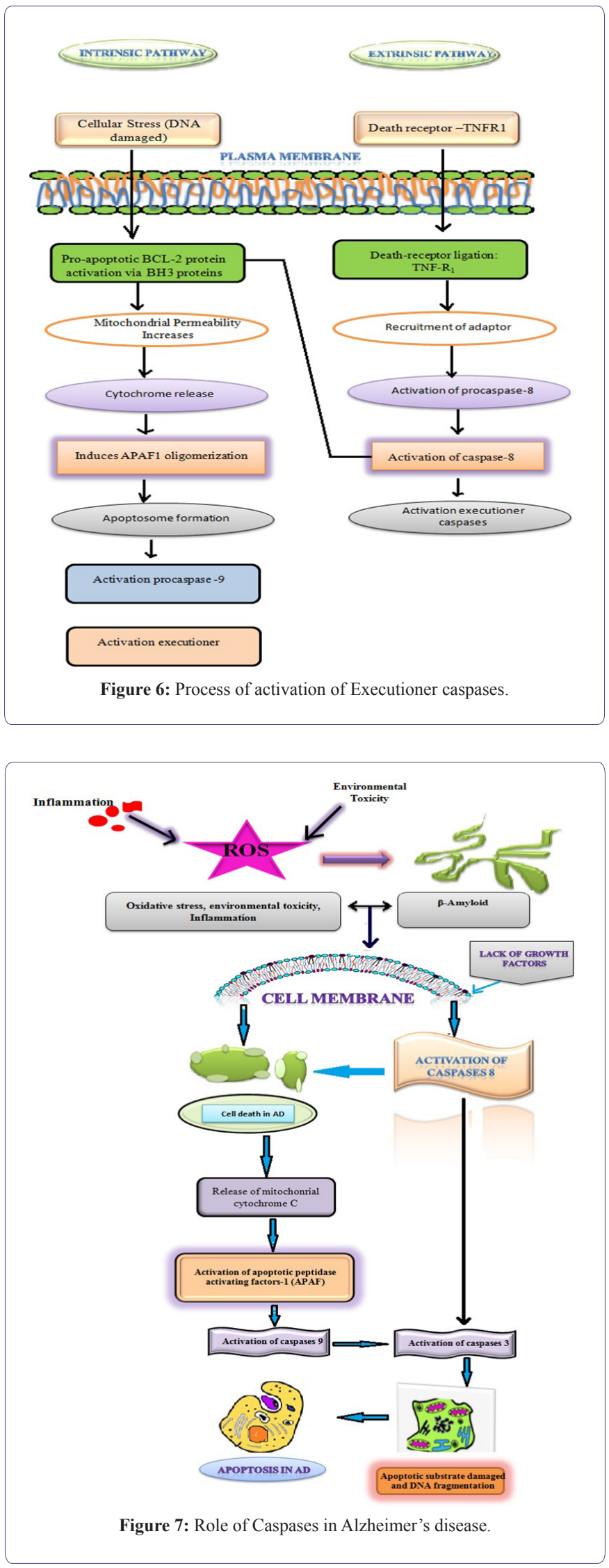
Lastly, these studies provide lot of information which supports the activation of apoptotic pathways during the course of the disease progression in $\mathrm{AD}$. Moreover, the role of caspases in $\mathrm{AD}$ is too much wider because the production of $A \beta$ is also associated with their activation. Hence the number of studies suggest that caspases may be showing their proximal role in the disease mechanisms underlying $\mathrm{AD}$ including promoting $\mathrm{A} \beta$ formation as well as linking plaques to NFTs [56] (Figure 8).

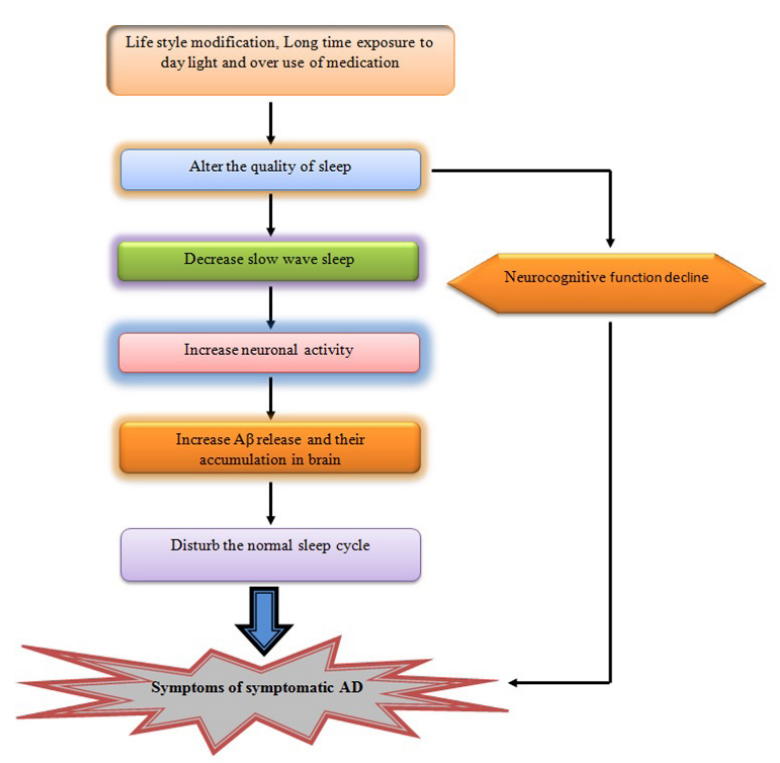

Figure 8: Sleep disturbances and Alzheimer disease.

\section{Role of sleep changes in Alzheimer's disease}

Alzheimer's Disease (AD) is a chronic neurodegenerative disorder that causes degeneration of CNS neurons thereby debilitating symptoms like loss of memory, interrupted speech and inability to carry out daily activities [57]. In AD the excessive loss of neuronal function leads to decrease mental abilities which may also disrupt the sleep/wake cycle, responsible for sleep problems, nighttime wandering, and agitation. In AD sleep the percentage of sleep disruption depends upon the severity of disease like those which are at early stages of AD may suffer more than usual [58]. As the disease is at initiation level, patients may begin to sleep during the day and awaken frequently throughout the night. Patients with more advanced in AD they sleep very rarely for long time periods. This also changes daily alterations in body temperature, sleep, wakefulness, and metabolism may also be sometimes disrupted in older adults.

Several reports have evidenced that sleep disruptions may be worse in patients with $\mathrm{AD}$ and due to this patient may lose the ability to stay asleep or keep alert during disease progresses [59]. Sleep problems may also increase the incidence of agitation among AD patient according to the results proofed by various reports [60]. Similarly, a term is used for this type of agitated behavior in $\mathrm{AD}$ that is "sundowning" mostly occurs in the evening schedule in various patients. This increased agitation behavior may be explained by sleepiness or may be more troublesome to caregivers during evening time [61]. But overall this creates a sleep apnea result in severe stress for caregivers and among $\mathrm{AD}$ patients which are on care therapy in nursing homes instead of at home. At initial stage this Sundown Syndrome is associated with increased stress, mental confusion and restlessness in patients due to which they are more prone to dementia that is commonly associated with $\mathrm{AD}[62]$.

The non-pharmacological factors which control the progression of $\mathrm{AD}$ are: firstly to make consistent sleeping, secondly change stressful lifestyle and lastly to do physical exercise. Physical activity is the best treatment for Alzheimer's, which also encourage patient for night sleep. Decrease the use of CNS stimulants like caffeine at night if a night's sleep is needed. Some evidence also supports the exogenous use of melatonin in combination with other antioxidants like lycopene or vitamin $\mathrm{E}$ can be used to induce sleep and preventing neurodegeneration [63]. Other pharmacological agents which are useful for the treatment of sleep deprivation induced or neurodegeneration induced $\mathrm{AD}$ are: Acetylcholinesterase inhibitor like donepezil which slows the cognitive decline in some patients but its major adverse effect is it can cause nighttime stimulation and is reported to promote nightmares in AD patients. Others like atypical antipsychotics and selective serotonin reuptake inhibitors are proved to be useful therapeutic agents [64].

\section{Conclusion}

$\mathrm{AD}$ is extremely complicated neurodegenerative disorder occurs due to the accumulation and overproductions of $\beta$-amyloid, tau formation by stressful lifestyle but the exact mechanism is still unknown. There are a number of molecular targets described which reflect the pathophysiology of AD but neurodegeneration have been speculated to occur through number of other factors also including environmental, genetic predisposition but oxidative stress and free radical generation are a prominent one. At present for the treatment of AD number of drugs like antioxidants and other pharmacological agents has been used but all provide symptomatic relief. So, there is a need for treatments which reduces the $\beta$-amyloid plaque formation or increases their elimination from CNS thereby reducing the oxidative stress. In this review, we have combined a number of molecular pathways involved in the pathogenesis of AD. Therefore either the inhibition of these pathways or the use of their antagonist may divert or decreases the progress of neurodegeneration in $\mathrm{AD}$.

\section{References}

1. Woods LT, Ajit D, Camden JM, Erb L, Weisman GA (2016) Purinergic receptors as potential therapeutic targets in Alzheimer's disease. Neuropharmacology 104: 169-179.

2. Guo T, Noble W, Hanger DP (2017) Roles of tau protein in health and disease. Acta Neuropathol 133: 665-704.

3. Fang D, Zhang Z, Li H, Yu Q, Douglas JT, et al. (2016) Increased electron paramagnetic resonance signal correlates with mitochondrial dysfunction and oxidative stress in an Alzheimer's disease mouse brain. J Alzheimers Dis 51: 571-580.

4. Kudo T (2016) Basic Theory of Pharmacology for Alzheimer's Disease. In Practical Pharmacology for Alzheimer's Disease. Springer International Publishing 1-25.

5. Godefroy O, Barbay M, Andriuta, D, Tir M, Roussel M (2017) Global Hypoactivity and Apathy. In Neuropsychiatric Symptoms of Cognitive Impairment and Dementia. Springer International Publishing 71-91. 
Citation: Rana A, Awasthi A, Kumar D, Singh S, Singh S (2018) Alzheimer's Disease Silent Killer of Memory: A Review on Pathological Mechanisms. J Alzheimers Neurodegener Dis 4: 017.

6. Schmitt K, Grimm A, Eckert A (2017) Amyloid- $\beta$-Induced Changes in Molecular Clock Properties and Cellular Bioenergetics. Front Neurosci 11: 124

7. Maluach AM, Misquitta KA, Prevot TD, Fee C, Sibille E, et al. (2017) Increased Neuronal DNA/RNA Oxidation in the Frontal Cortex of Mice Subjected to Unpredictable Chronic Mild Stress. Chronic Stress 1.

8. Winkler EA, Sagare AP, Zlokovic BV (2014) The Pericyte: A Forgotten Cell Type with Important Implications for Alzheimer's Disease? Brain Pathol 24: 371-386.

9. Huang S, Wang Y (2017) Golgi structure formation, function, and post-translational modifications in mammalian cells. F1000Res 6: 2050.

10. Joshi G, Bekier MI, Wang Y (2015) Golgi fragmentation in Alzheimer's disease. Front Neurosci 24: 340

11. Sathyan S, Barzilai N, Atzmon G, Milman S, Ayers E, et al. (2017) Association of anti-inflammatory cytokine IL10 polymorphisms with motoric cognitive risk syndrome in an Ashkenazi Jewish population. Neurobiol Aging 58: 238.

12. Li K, Wei Q, Liu FF, Hu F, Xie AJ, et al. (2017) Synaptic Dysfunction in Alzheimer's Disease: $\mathrm{A} \beta$, Tau, and Epigenetic Alterations. Mol Neurobiol 55: 3021-3032.

13. Watson R, Zibadi S (2017) Nutritional Modulators of Pain in the Aging Population (1st edn.). Academic Press, London, UK, Pg no: 314.

14. Miarons M, Cabib C, Barón FJ, Rofes L (2017) Evidence and decision algorithm for the withdrawal of antipsychotic treatment in the elderly with dementia and neuropsychiatric symptoms. Eur J Clin Pharmacol 73: 1389-1398.

15. Wildburger NC, Esparza TJ, LeDuc RD, Fellers RT, Thomas PM, et al. (2017) Diversity of amyloid-beta proteoforms in the Alzheimer's disease brain. Scientific Reports 7.

16. Willén K, Sroka A, Takahashi RH, Gouras GK (2017) Heterogeneous Association of Alzheimer's Disease-Linked Amyloid- $\beta$ and Amyloid- $\beta$ Protein Precursor with Synapses. J Alzheimers Dis 60: 511-524.

17. Wang X, Zhou X, Li G, Zhang Y, Wu Y, et al. (2017) Modifications and Trafficking of APP in the Pathogenesis of Alzheimer's Disease. Front Mol Neurosci 10: 294

18. Stroo E, Koopman M, Nollen EA, Mata-Cabana A (2017) Cellular Regulation of Amyloid Formation in Aging and Disease. Front Neurosci 11: 64.

19. Sweeney P, Park H, Baumann M, Dunlop J, Frydman J, et al. (2017) Protein misfolding in neurodegenerative diseases: implications and strategies. Transl Neurodegener 6: 6.

20. Tarasoff-Conway JM, Carare RO, Osorio RS, Glodzik L, Butler T, et al. (2015) Clearance systems in the brain-implications for Alzheimer disease. Nat Rev Neurol 11: 457-470.

21. Blonz ER (2017) Alzheimer's Disease as the Product of a Progressive Energy Deficiency Syndrome in the Central Nervous System: The Neuroenergetic Hypothesis. J Alzheimers Dis 60: 1223-1229.

22. Cardoso I, Santos LM, Alemi M (2016) Modulating Role of TTR in A Toxicity, from Health to Disease Exploring New Findings on Amyloidosis 1-71.

23. Economou NJ, Giammona MJ, Do TD, Zheng X, Teplow DB, et al. (2016) Amyloid $\beta$-protein assembly and Alzheimer's disease: Dodecamers of $A \beta 42$, but not of $A \beta 40$ seed fibril formation. J Am Chem Soc 138: $1772-1775$.

24. Sengupta U, Nilson AN, Kayed R (2016) The Role of Amyloid- $\beta$ Oligomers in Toxicity, Propagation, and Immunotherapy. EBioMedicine 6: $42-49$
25. Kudryavtseva AV, Krasnov GS, Dmitriev AA, Alekseev BY, Kardymon OL, et al. (2016) Mitochondrial dysfunction and oxidative stress in aging and cancer. Oncotarget 7: 44879-44905.

26. Selkoe DJ, Hardy J (2016) The amyloid hypothesis of Alzheimer's disease at 25 years. EMBO Mol Med 8: 595-608.

27. Karmiloff-Smith A, Al-Janabi T, D'Souza H, Groet J, Massand E, et al. (2016) The importance of understanding individual differences in Down syndrome. F1000Res 5.

28. Foraker J, Millard SP, Leong L, Thomson Z, Chen S, et al. (2015) The APOE Gene is Differentially Methylated in Alzheimer's Disease. J Alzheimers Dis 48: 745-755.

29. Cerasoli E, Ryadnov MG, Austen BM (2015) The elusive nature and diagnostics of misfolded $A \beta$ oligomers. Front Chem 3: 17.

30. Folch J, Petrov D, Ettcheto M, Abad S, Sánchez-López E, et al. (2016) Current Research Therapeutic Strategies for Alzheimer's Disease Treatment. Neural plasticity 1-15.

31. Zhou X, Li Y, Shi X, Ma C (2016) An overview on therapeutics attenuating amyloid $\beta$ level in Alzheimer's disease: targeting neurotransmission, inflammation, oxidative stress and enhanced cholesterol levels. Am J Transl Res 8: 246-269.

32. Medina M, Hernández F, Avila J (2016) New Features about Tau Function and Dysfunction. Biomolecules 6: 21.

33. Šimić G, Babić Leko M, Wray S, Harrington C, Delalle I, et al. (2016) Tau protein hyperphosphorylation and aggregation in Alzheimer's disease and other tauopathies, and possible neuroprotective strategies. Biomolecules 6: 6 .

34. Brunden KR, Lee VM, Smith AB 3rd, Trojanowski JQ, Ballatore C (2017) Altered microtubule dynamics in neurodegenerative disease: Therapeutic potential of microtubule-stabilizing drugs. Neurobiol Dis 105: 328-335.

35. Lepeta K, Lourenco MV, Schweitzer BC, Martino Adami PV, Banerjee P, et al. (2016) Synaptopathies: synaptic dysfunction in neurological disorders - A review from students to students. J Neurochem1 38: 785-805.

36. Singh SK, Srivastav S, Yadav AK, Srikrishna S, Perry G (2015) Overview of Alzheimer's Disease and Some Therapeutic Approaches Targeting $A \beta$ by Using Several Synthetic and Herbal Compounds. Oxid Med Cell Longev.

37. Alonso AD, Beharry C, Corbo CP, Cohen LS (2016) Molecular mechanism of prion-like tau-induced neurodegeneration. Alzheimers Dement 12: 1090-1097.

38. Pandey MK, DeGrado TR (2016) Glycogen Synthase Kinase-3 (GSK-3)-Targeted Therapy and Imaging. Theranostics 6: 571-593.

39. Ballatore C, Smith AB, Lee VMY, Trojanowski JQ, Brunden KR (2017) Microtubule-Stabilizing Agents for Alzheimer's and Other Tauopathies. Alzheimer's Disease 159-179.

40. Watanabe H, Ono M, Saji H (2015) Novel PET/SPECT probes for imaging of tau in Alzheimer's disease. Sci World J.

41. Dai CL, Tung YC, Liu F, Gong CX, Iqbal K (2017) Tau passive immunization inhibits not only tau but also A $\beta$ pathology. Alzheimers Res Ther 9: 1 .

42. Halliday MR, Rege SV, Ma Q, Zhao Z, Miller CA, et al. (2016) Accelerated pericyte degeneration and blood-brain barrier breakdown in apolipoprotein E4 carriers with Alzheimer's disease. J Cereb Blood Flow Metab 36: 216-227.

43. Sharma P, Jha AB, Dubey RS, Pessarakli M (2012) Reactive oxygen species, oxidative damage and antioxidative defense mechanism in plants under stressful conditions. Journal of Botany 1-26. 
44. Kaur R, Mehan S, Singh S (2018) Understanding multifactorial architecture of Parkinson's disease: Pathophysiology to management. Neurol Sci.

45. Sheng ZH (2014) Mitochondrial trafficking and anchoring in neurons: New insight and implications. J Cell Biol 204: 1087-1098.

46. Perry G, Cash AD, Smith MA (2002) Alzheimer disease and oxidative stress. J Biomed Biotechnol 2: 120-123.

47. Filomeni G, De Zio D, Cecconi F (2015) Oxidative stress and autophagy: The clash between damage and metabolic needs. Cell Death Differ 22: $377-388$.

48. Bariar B, Vestal CG, Richardson C (2013) Long-term effects of chromatin remodeling and DNA damage in stem cells induced by environmental and dietary agents. J Environ Pathol Toxicol Oncol 32: 307-327.

49. Paravicini TM, Touyz RM (2008) NADPH oxidases, reactive oxygen species, and hypertension: clinical implications and therapeutic possibilities. Diabetes Care 31: 170-180.

50. Yan MH, Wang X, Zhu X (2013) Mitochondrial defects and oxidative stress in Alzheimer disease and Parkinson disease. Free Radic Biol Med 62: $90-101$.

51. Debevec T, Millet GP, Pialoux V (2017) Hypoxia-induced oxidative stress modulation with physical activity. Front Physiol 8: 84.

52. Chang HY, Yang X (2000) Proteases for cell suicide: Functions and regulation of caspases. Microbiol Mol Biol Rev 64: 821-846.

53. Gerl R, Vaux DL (2005) Apoptosis in the development and treatment of cancer. Carcinogenesis 26: 263-270.

54. Pontillo A, Catamo E, Arosio B, Mari D, Crovella S (2012) NALP1/ NLRP1 genetic variants are associated with Alzheimer disease. Alzheimer Dis Assoc Disord 26: 277-281.
55. Kumasaka DK, Galvan V, Head E, Rohn TT (2009) Caspase cleavage of the amyloid precursor protein is prevented after overexpression of bcl-2 in a triple transgenic mouse model of Alzheimer's disease. Int J Physiol Pathophysiol Pharmacol 1: 48-56.

56. D'amelio M, Cavallucci V, Middei S, Marchetti C, Pacioni S, et al. (2011) Caspase-3 triggers early synaptic dysfunction in a mouse model of Alzheimer's disease. Nat Neurosci 14: 69-76.

57. Jucker M, Walker LC (2011) Pathogenic protein seeding in Alzheimer disease and other neurodegenerative disorders. Ann Neurol 70: 532-540.

58. Bliwise DL (2004) Sleep disorders in Alzheimer's disease and other dementias. Clin Cornerstone 6: 16-28.

59. Khachiyants N, Trinkle D, Son SJ, Kim KY (2011) Sundown syndrome in persons with dementia: an update. Psychiatry Investig 8: 275-287.

60. Phillips B, Ancoli-Israel S (2001) Sleep disorders in the elderly. Sleep Med 2: 99-114.

61. Volicer L, Harper DG, Manning BC, Goldstein R, Satlin A (2001) Sundowning and circadian rhythms in Alzheimer's disease. Am J Psychiatry 158: 704-711.

62. Jelicic M, Bosma H, Ponds RW, Van Boxtel MP, Houx PJ, et al. (2002) Subjective sleep problems in later life as predictors of cognitive decline. Report from the Maastricht Ageing Study (MAAS). Int J Geriatr Psychiatry 17: 73-77.

63. Cardinali DP, Furio AM, Brusco LI (2010) Clinical Aspects of Melatonin Intervention in Alzheimer's Disease Progression. Curr Neuropharmacol 8: 218-227.

64. Cacabelos R (2007) Donepezil in Alzheimer's disease: From conventional trials to pharmacogenetics. Neuropsychiatr Dis Treat 3: 303-333. 


\section{di \\ нита}

Journal of Anesthesia \& Clinical Care

Journal of Addiction \& Addictive Disorders

Advances in Microbiology Research

Advances in Industrial Biotechnology

Journal of Agronomy \& Agricultural Science

Journal of AIDS Clinical Research \& STDs

Journal of Alcoholism, Drug Abuse \& Substance Dependence

Journal of Allergy Disorders \& Therapy

Journal of Alternative, Complementary \& Integrative Medicine

Journal of Alzheimer's \& Neurodegenerative Diseases

Journal of Angiology \& Vascular Surgery

Journal of Animal Research \& Veterinary Science

Archives of Zoological Studies

Archives of Urology

Journal of Atmospheric \& Earth-Sciences

Journal of Aquaculture \& Fisheries

Journal of Biotech Research \& Biochemistry

Journal of Brain \& Neuroscience Research

Journal of Cancer Biology \& Treatment

Journal of Cardiology \& Neurocardiovascular Diseases

Journal of Cell Biology \& Cell Metabolism

Journal of Clinical Dermatology \& Therapy

Journal of Clinical Immunology \& Immunotherapy

Journal of Clinical Studies \& Medical Case Reports

Journal of Community Medicine \& Public Health Care

Current Trends: Medical \& Biological Engineering

Journal of Cytology \& Tissue Biology

Journal of Dentistry: Oral Health \& Cosmesis

Journal of Diabetes \& Metabolic Disorders

Journal of Dairy Research \& Technology

Journal of Emergency Medicine Trauma \& Surgical Care

Journal of Environmental Science: Current Research

Journal of Food Science \& Nutrition

Journal of Forensic, Legal \& Investigative Sciences

Journal of Gastroenterology \& Hepatology Research

Journal of Gerontology \& Geriatric Medicine
Journal of Genetics \& Genomic Sciences

Journal of Hematology, Blood Transfusion \& Disorders

Journal of Human Endocrinology

Journal of Hospice \& Palliative Medical Care

Journal of Internal Medicine \& Primary Healthcare

Journal of Infectious \& Non Infectious Diseases

Journal of Light \& Laser: Current Trends

Journal of Modern Chemical Sciences

Journal of Medicine: Study \& Research

Journal of Nanotechnology: Nanomedicine \& Nanobiotechnology

Journal of Neonatology \& Clinical Pediatrics

Journal of Nephrology \& Renal Therapy

Journal of Non Invasive Vascular Investigation

Journal of Nuclear Medicine, Radiology \& Radiation Therapy

Journal of Obesity \& Weight Loss

Journal of Orthopedic Research \& Physiotherapy

Journal of Otolaryngology, Head \& Neck Surgery

Journal of Protein Research \& Bioinformatics

Journal of Pathology Clinical \& Medical Research

Journal of Pharmacology, Pharmaceutics \& Pharmacovigilance

Journal of Physical Medicine, Rehabilitation \& Disabilities

Journal of Plant Science: Current Research

Journal of Psychiatry, Depression \& Anxiety

Journal of Pulmonary Medicine \& Respiratory Research

Journal of Practical \& Professional Nursing

Journal of Reproductive Medicine, Gynaecology \& Obstetrics

Journal of Stem Cells Research, Development \& Therapy

Journal of Surgery: Current Trends \& Innovations

Journal of Toxicology: Current Research

Journal of Translational Science and Research

Trends in Anatomy \& Physiology

Journal of Vaccines Research \& Vaccination

Journal of Virology \& Antivirals

Submit Your Manuscript: http://www.heraldopenaccess.us/Online-Submission.php 